\title{
Active in Situ Biomonitoring of Pesticide Pulses Using Gammarus spp. in Small Tributaries of Lake Constance
}

\author{
Almut Gerhardt ${ }^{1}$, Margie Koster ${ }^{2}$, Frank Lang ${ }^{3}$, Vera Leib ${ }^{4}$ \\ ${ }^{1}$ LimCo International GmbH, Konstanz, Germany; ${ }^{2}$ Amt für Umwelt Kanton Thurgau, Frauenfeld, Switzerland; ${ }^{3}$ Interkantonales \\ Labor Schaffhausen, Schaffhausen, Switzerland; ${ }^{4}$ Amt für Umwelt und Energie Kanton St. Gallen, St. Gallen, Switzerlan. \\ Email: almutg@web.de
}

Received April 11 $1^{\text {th }}, 2012$; revised May 14 ${ }^{\text {th }}, 2012$; accepted June $15^{\text {th }}, 2012$

\begin{abstract}
Gammarids are important members of a stream's macrozoobenthos biocoenosis and food web. Moreover, they proved to be very sensitive towards different types of pollution. GamTox ${ }^{\mathrm{TM}}$ is a new in situ ecotoxicity test, based on survival and feeding behavior of caged gammarids for active monitoring of small streams in agricultural areas. GamTox ${ }^{\mathrm{TM}}$ has been applied in two streams with specific pollution problems in the catchment of Lake Constance. Ten organisms were exposed in 5 replicates in flow through test tubes containing one conditioned alder leaf, placed in baskets which were attached in the stream bottom and on the banks. Each week, the number of living animals was counted, the percentage of leaf skeletized estimated in semi-quantitative classes and a new elder leaf provided. Dead organisms were removed. Simultaneously, chemical analyses of pesticides and nutrients (N-compounds, $\mathrm{P}$ ) were performed on cumulative water samples over one week. Moreover, macrozoobenthos was collected and determined according to the IBCH method, and the SPEAR index calculated. GamTox ${ }^{\mathrm{TM}}$ proved to be very sensitive to detect pesticides, copper as well as nutrients, both during acute pollution pulses and chronic exposures of up to 6 weeks. Survival turned out to be a more sensitive and less variable parameter than feeding. GamTox ${ }^{\mathrm{TM}}$ is easy to perform and directly provides a measure of ecotoxicological effects of toxicant/nutrient mixtures, which cannot be predicted by biological indices based on macrozoobenthos data such as IBCH and SPEAR-index. This study was co-financed by the InterReg IV project "Ökotoxikologischer Index im Bodenseeraum”, no. 227 (2011-2013) supported by the EFRE.
\end{abstract}

Keywords: Active Biomonitoring; Gammarus; Field Test; Ecotoxicology

\section{Introduction}

Small streams in agricultural areas are subjected to many different stressors, such as morphological degradation, intensive solar radiation in lack of shade by woody bank vegetation, extremely varying discharge such as low water levels during summer with the risk for drought as well as pollution pulses by pesticides and nutrients. At low water levels pesticide concentrations are expected to increase due to concentration effects in the remaining water pools exposed to high evaporation and sometimes additional water abstraction for irrigation. In the near future, such extremes might become more frequent due to climate change with increasing summer temperatures and long lasting drought periods. Although this type of small stream is expected to undergo serious changes it has not yet been considered in the EU Water Framework Directive (2000/60/EG), which concentrates on streams with a catchment $>10 \mathrm{~km}^{2}$. The Directive postulates an ecologically oriented holistic approach in surface water management, aiming at a good ecological (biological, hydromorphological) and chemical (reduction of 33 priority substances below the levels of their resp. acute/ chronic environmental quality standards) status. Environmental quality standards legislation for the priority substances has been in power since 2009 (2008/105/EG), the additional groundwater directive (2006/118/EG) sets quality standards for nitrate and plant protection products. However, overall the current approach is a "single substance" or "substance group" approach neglecting mixture toxicity effects. It is an accepted fact that combinations of different types of contaminants and nutrients ("effect-based approaches") and metabolites/degradation products might be more toxic than the parent compounds. Moreover, as environmental quality standards are derived only from literature data based on acute toxicity data for standard test species such as Daphnia spp., extrapolation from lab/field as well as extrapolation to other species incorporates high uncertainties, which is currently accounted for by the use of safety factors.

Concerning these drawbacks a new trend in incorporating in situ ecotoxicity testing or "active biomonitor- 
ing" as an additional module/pillar for integrated triadbased water quality assessment and monitoring focusing on the benthic community as protection goal has emerged $[1,2]$. Until now in situ ecotoxicological assessment and active biomonitoring of water quality with indigenous indicator species has not been implemented as standard method in regulatory agencies in either Switzerland or the European Union.

Gammarids form a group with more than hundred species and represent an important key taxon in small streams in the Northern Hemisphere: both their abundance and their role in the food web (detritus cycling, controlling the microbial loop), their biological indicator function ( $\beta$-mesosaprob) and their wide distribution combined with their sensitivity towards many pollutants make them perfect test species in applied aquatic ecotoxicology and integrated triad-based water quality assessment according to the WFD [3]. GamTox ${ }^{\mathrm{TM}}$ is a novel low-cost test based on behavior and survival that has recently been developed for both laboratory and in situ application, in order to bridge the extrapolation gap [3]. In situ tests with gammarids are still rare. Some approaches have been performed in artificial streams [4], in situ to study metal pollution [5]. Bloor \& Banks assessed landfill leachates with in situ tests using mixed species assemblages of Asellus aquaticus and Gammarus pulex [6]. Maltby et al. studied effects of waste water treatment plants on gammarids in situ [7]. All papers conclude Gammarus spp. to be sensitive and ecologically relevant test species.

The aims of this study were to 1) develop a low-cost/ effort field Gammarus test $\left(\mathrm{GamTox}^{\mathrm{TM}}\right)$ to assess the biological relevance of both acute and chronic pollution, to be assessed directly in situ; 2) validate and implement this test in routine biomonitoring by water authorities in comparison to biological water quality indices and chemical analyses; and 3) apply GamTox ${ }^{\mathrm{TM}}$ with both $G$. pulex and G. fossarum in two streams with unknown pollution problems at sites where gammarids are lacking, hence finding explanations for this fact.

\section{Material and Methods}

\subsection{Streams}

Small streams below $10 \mathrm{~km}^{2}$ catchment have been chosen for this study, because they are extremely affected by varying water levels, input from surface runoff due to rainfall events, climate change and summer drought/ stagnation and lack of woody vegetation on the banks. Mostly such streams are canalized and agricultural fields often extend until the banks, hence next to hydromorphological monotony and temperature extremes during summer chemical stress due to a mixture of nutrients and pesticides additionally affects the aquatic fauna.
GamTox $^{\mathrm{TM}}$ has been validated in two brooks in the catchment of Lake Constance, an area with intense agriculture, esp. orchards (esp. apples, wine), flowers and vegetables. Both streams show specific point pollution problems, which were used to validate GamTox ${ }^{\mathrm{TM}}$.

The Hornbach receives drainage from both a horticulture nursery and agriculture, and the Häftlibach receives pollution from a poulty farm and agriculture. Hornbach (Canton Thurgau) and Häftlibach (Canton St. Gallen) flow into lake Constance, which is an important drinking water reservoir for both Swiss and German people. The Hornbach flows through agricultural land, the exposure sites were chosen directly above (737983/274755) and below $(738181 / 274633)$ a horticulture garden centre, as well as further downstream (739789/274637) close to the shore of Lake Constance. Up to 22 different pesticides have been recorded in the stream, ca. 30\% in concentration levels above $0.1 \mu \mathrm{g} / \mathrm{L}$. Below the horticulture nursery no gammarids have been observed in contrast to above the horticulture nursery where both G. pulex and $G$. fossarum occur in large amounts and viable populations. Gammarus pulex was collected from the Othmarbach (738757/273751), which was also the reference stream, being a small tributary of the Hornbach nearby the other sites and flowing through a woody stretch with natural stream structure and substrate.

The Häftlibach also flows through agricultural land, the three sites are situated along the stream, whereby the uppermost site (Mörschwil, 749654/259246) receives pollution from a local poultry farm. The site Meggenmühle (750906/259889) is situated further downstream in an agricultural area, the site Steinach (751921/262481, Canton Thurgau) is situated close to the shore of Lake Constance. Gammarus fossarum is found at the latter two sites. The Chesselbach (750637/260188) with natural streambed structure and woody vegetation at the banks served as reference. Gammarus fossarum was collected for the exposure experiments.

\subsection{Test Species}

Gammarids are key species in European streams: Dominant both in numbers and biomass they represent prey species for both large invertebrates and fish. As shredders they play an important role in the decay of coarse detritus, affecting the microbial loop and the cycling of $\mathrm{C}$ and $\mathrm{N}$ in streams $[3,8]$. European gammarids, esp. $G$. pulex (L.) and even more G. fossarum Koch 1835, are sensitive to pollution by nutrients and pesticides, their sensitivity being mostly comparable to that of daphnids, the standard test species in ecotoxicology. However, gammarids are sometimes even more sensitive than daphnids, e.g. for pyrethroids [3,9]. Thus, they are the optimal candidates for active in situ pollution biomoni- 
toring in running waters. Their sensitive response to pollution follows the Stepwise Stress Model [10], showing a cascade of subsequent stress responses with avoidance (locomotion, drift), followed by increased ventilation time and frequency followed ultimately by morbidity [10]. Moreover, feeding behavior has been shown to represent a sensitive response towards micropollutants [4]. In several streams in Switzerland a decrease of Gammarus spp. abundance or even a lack of gammarids has been observed during past routine monitoring [11]. Even though gammarids are highly mobile (drift, upstream migration) sustainable recolonisation after a pollution event might still take up to several years even if unaffected populations are available in the catchment [11].

\subsection{Experimental Setup}

Gammarids were collected in the resp. reference streams (G. pulex from Othmarbach for the Hornbach experiment, G. fossarum from Chesselbach for the Häflibach experiment) and transported to the exposure sites. Ten randomly chosen visually healthy subadult gammarids (both sexes) were placed in each cage and 5 cages were exposed at each site. The cages were made of transparent plexiglass tubes $(15 \mathrm{~cm}$ length, $5 \mathrm{~cm}$ diameter) with two screw rings at each end. The rings contained a nylon net (0.5 mm mesh size) to 1) allow water and fine detritus passage through the cage but 2) avoid escape resp. entrance of invertebrates. The transparent plexiglass tube protected the gammarids from hydromorphological stress and did not affect the natural photoperiod. Each plexiglass cage contained a conditioned alder leaf as food and substrate. Five replicate cages were exposed next to each other in a plastic basket, which was positioned directly on the sediment in direction of the current and attached with steel poles and ropes in the stream bed resp. on the banks above water level. Large stones were placed on the basket to simulate a natural habitat and provide additional weight to keep the basket in position (Figure 1).

Previously, fresh green alder leaves had been plucked from an alder tree in the catchment, using only intact leaves without holes due to insect feeding. The leaves had been watered in dechlorinated aerated tap water for about 4 days at room temperature with daily replacement of the water, until dissolution of the colors and maceration of the leaves. After drying at room temperature the leaves were stored in closed plastic bags until use in the experiments. Each week the cages were controlled as follows: the animals were counted, dead ones removed, the percentage leaf surface sceletized was estimated as 0 , $<25 \%,<50 \%,<75 \%,<100 \%$ and thereafter replaced by a new leaf. The experiments ran for up to 6 weeks during the main time of pesticide application in a dry period in early summer 2011.

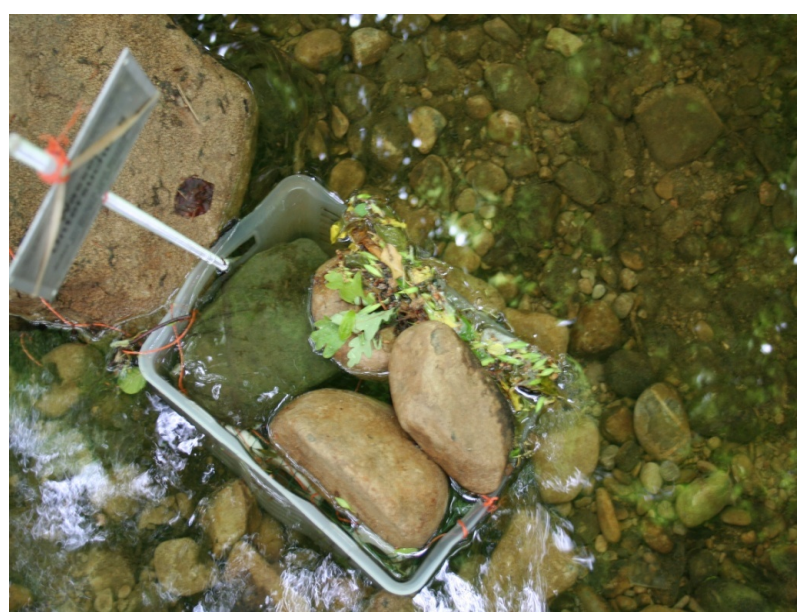

Figure 1. Experimental setup: Exposure of a basket with 5 plexiglass cages in the Hornbach at the downstream site. Photo A. Gerhardt.

\subsection{Chemical Analyses}

At all sites automatic water samplers were installed collecting periodically water into a cumulative volume of $4 \mathrm{~L}$ after 7 days. The samples were filtered directly and stored in the fridge $\left(4^{\circ} \mathrm{C}\right)$ until pesticide analysis. Analyses were carried out either in the laboratories of the cantons St. Gallen and Schaffhausen or at the Water Technology Center in Karlsruhe (Germany) using LCMS-MS respectively GC-MS. Nutrients were analysed in-house using common state of the technology as (IC) ion chromatography, FIA flow injection analysis, DOC, $\mathrm{pH}$ and so on.

\subsection{Statistical Analysis}

Survival data (absolute numbers) and feeding rates (\%) were analyzed with non-parametric ANOVA on ranks (Friedmann tests) considering time dependent data as repeated measures (STATISTICA 10.0). Post-hoc Wilcoxon tests confirmed significant differences in pairwise comparisons $\left(\mathrm{p}<0.05^{*}, \mathrm{p}<0.01^{* *}, \mathrm{p}<0.001^{* * *}\right.$ ).

\section{Results}

\subsection{Chemical Analyses}

\subsubsection{Hornbach}

During the exposure period the $\mathrm{pH}$ values in the Hornbach varied between 8.00 and 8.33 , conductivity between 525 and $596 \mu \mathrm{S} / \mathrm{cm}$, comparable at all sites. Nitrite and phosphate values were elevated only below the horticulture nursery, there reaching up to $0.32 \mathrm{mg} \mathrm{NO} / / \mathrm{L}$ (bad water quality) and $0.43 \mathrm{mg} \mathrm{PO} / \mathrm{L}$ (bad water quality). Water temperature was between $15^{\circ} \mathrm{C}$ and $20^{\circ} \mathrm{C}$ at all locations.

Pesticide analysis revealed the Othmarbach to be rela- 
tively unaffected by anthropogenous pollution during the exposure period; the densely wooded embankment might serve as a good buffer against agricultural pesticide input. In total, many pesticides could be measured, mostly in moderate concentrations (Table 1). The most polluted site in the Hornbach was the site below the horticulture nursery, followed by the downstream site. The least polluted site was the one above the horticulture nursery. Chlorazidon, Metolachlor and AMPA were found at all sites, generally the $1^{\text {st }}$ weekly sample contained higher concentration levels than the $2^{\text {nd }}$ weekly sample. Imidacloprid, Iprodion and Glyphosat were elevated at the site below compared to above the horticulture nursery as well as Diazinon in the $2^{\text {nd }}$ weekly sample (Table 1). Endosulfan was only found below the horticulture nursery. Diuron was only found at the downstream site. Many of the in total 96 analysed substances were below or around the detection limit and therefore not considered here in the ecotoxicological framework and not listed in Tables 1 and 2.

\subsubsection{Häftlibach}

In the Häftlibach $\mathrm{pH}$ levels were between 8.2 and 8.4 and temperature varied between $13^{\circ} \mathrm{C}$ and $17^{\circ} \mathrm{C}$, where of the

Table 1. Nutrients and pesticides found in 2 subsequent weekly cumulative samples in the Hornbach during May-June 2011: a) $1^{\text {st }}$ week; b) $2^{\text {nd }}$ week: Critical concentrations are marked in red. Nd: Not detected, below detection limit $(0.01 \mu \mathrm{g} / \mathrm{L})$, not determined; Sites: Othmarbach (reference); Hornbach: Above horticulture centre, below horticulture centre, downstream site.

\begin{tabular}{|c|c|c|c|c|}
\hline Analyt & Othmarbach & Above hort. & Below hort. & Downstream \\
\hline $\mathrm{pH}$ & 8.2 & 8.2 & 8 & 8 \\
\hline C. $(\mu \mathrm{S} / \mathrm{cm})$ & 563 & 525 & 576 & 596 \\
\hline $\mathrm{NH}_{4}-\mathrm{N}(\mathrm{mg} / \mathrm{L})$ & 0.06 & 0.22 & 0.22 & 0.05 \\
\hline $\mathrm{NO}_{2}-\mathrm{N}(\mathrm{mg} / \mathrm{L})$ & 0.04 & 0.05 & 0.27 & 0.03 \\
\hline $\mathrm{NO}_{3}-\mathrm{N}(\mathrm{mg} / \mathrm{L})$ & 2.9 & 2.9 & 4.9 & 4.2 \\
\hline P-tot $(\mathrm{mg} / \mathrm{L})$ & 0.12 & 0.07 & 0.47 & 0.28 \\
\hline Atrazin (ng/L) & $\mathrm{Nd}$ & $\mathrm{Nd}$ & $\mathrm{Nd}$ & 0.02 \\
\hline Chlorazidon $(\mu \mathrm{g} / \mathrm{L})$ & 0.1 & 0.12 & 0.1 & 0.1 \\
\hline Diazinon $(\mu \mathrm{g} / \mathrm{L})$ & $\mathrm{Nd}$ & 0.11 & 0.07 & 0.08 \\
\hline Diuron $(\mu \mathrm{g} / \mathrm{L})$ & $\mathrm{Nd}$ & $\mathrm{Nd}$ & $\mathrm{Nd}$ & 0.07 \\
\hline $\operatorname{MCPA}(\mu \mathrm{g} / \mathrm{L})$ & $\mathrm{Nd}$ & 0.08 & 0.06 & $\mathrm{Nd}$ \\
\hline $\operatorname{MCPP}(\mu \mathrm{g} / \mathrm{L})$ & $\mathrm{Nd}$ & 0.35 & 0.27 & 0.25 \\
\hline Metolachlor $(\mu \mathrm{g} / \mathrm{L})$ & 0.03 & 0.07 & 0.05 & 0.06 \\
\hline Simazin $(\mu \mathrm{g} / \mathrm{L})$ & 0.12 & 0.19 & 0.11 & 0.14 \\
\hline Terbutylazin $(\mu \mathrm{g} / \mathrm{L})$ & $\mathrm{Nd}$ & 0.05 & $\mathrm{Nd}$ & 0.05 \\
\hline AMPA $(\mu \mathrm{g} / \mathrm{L})$ & 0.06 & 0.27 & 0.29 & 0.25 \\
\hline Glyphosat $(\mu \mathrm{g} / \mathrm{L})$ & 0.07 & 0.42 & 0.53 & 0.5 \\
\hline Dimethylsulfonamid $(\mu \mathrm{g} / \mathrm{L})$ & $\mathrm{Nd}$ & 0.1 & 0.23 & 0.14 \\
\hline Endosulfan $(\mu \mathrm{g} / \mathrm{L})$ & $\mathrm{Nd}$ & $\mathrm{Nd}$ & 0.06 & $\mathrm{Nd}$ \\
\hline Fluazifop $(\mu \mathrm{g} / \mathrm{L})$ & $\mathrm{Nd}$ & 0.04 & 0.03 & $\mathrm{Nd}$ \\
\hline Imidacloprid $(\mu \mathrm{g} / \mathrm{L})$ & $\mathrm{Nd}$ & $\mathrm{Nd}$ & 0.08 & 0.03 \\
\hline Iprodion $(\mu \mathrm{g} / \mathrm{L})$ & 0.03 & 0.08 & 0.36 & 0.15 \\
\hline Metolachlor $(\mu \mathrm{g} / \mathrm{L})$ & 0.21 & $\mathrm{Nd}$ & $\mathrm{Nd}$ & 0.05 \\
\hline Pirimicarb $(\mu g / L)$ & $\mathrm{Nd}$ & 0.12 & $\mathrm{Nd}$ & 0.06 \\
\hline
\end{tabular}




\section{Continued}

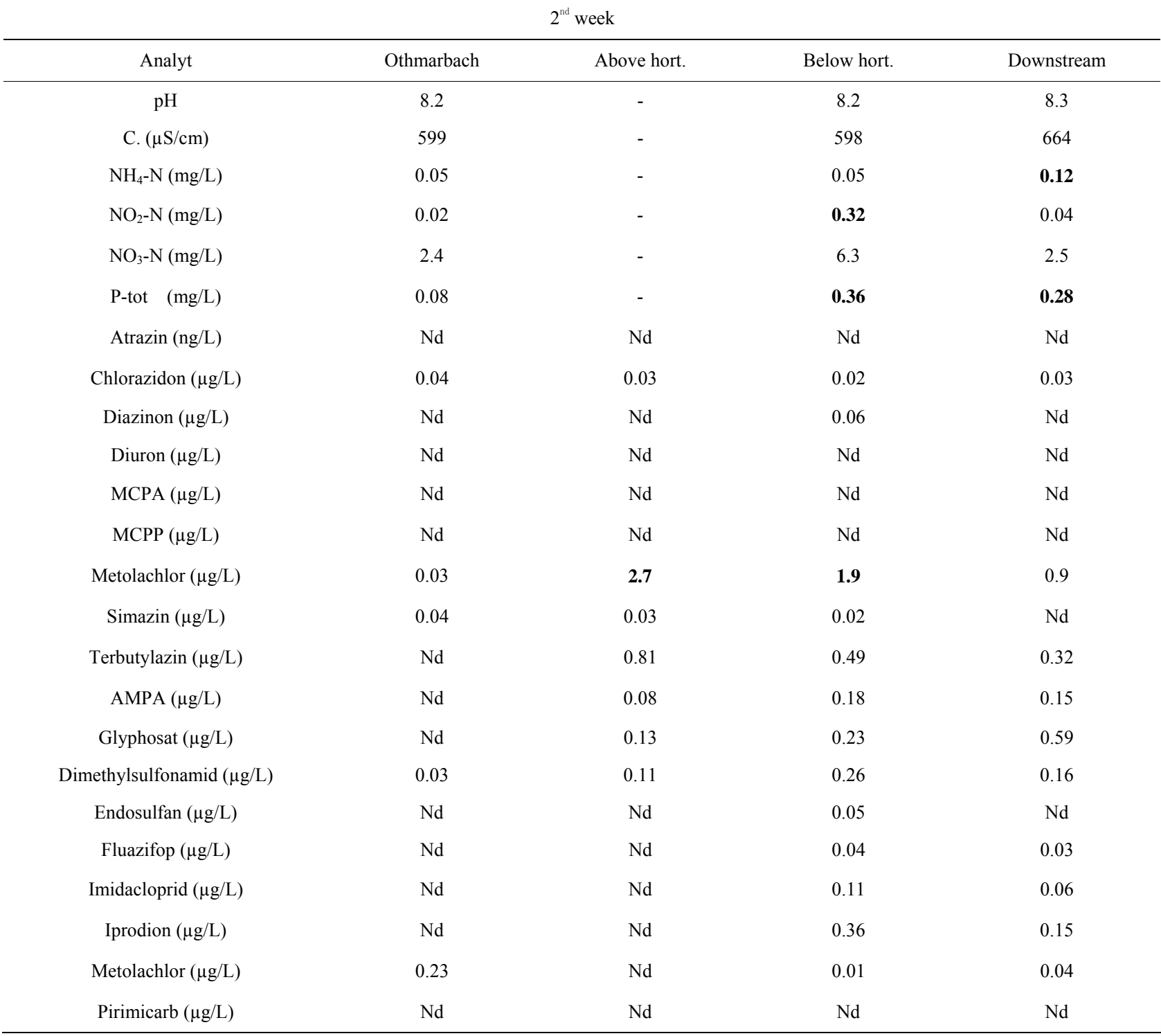

lower levels were measured in the second week of exposure. Conductivity was slightly higher than in the Hornbach $(612-686 \mu \mathrm{S} / \mathrm{cm})$, however during the second week of exposure it sank, esp. at the downstream site to $341-580 \mu \mathrm{S} / \mathrm{cm}$. At Mörschwil, the uppermost site DOC $(7.5 \mathrm{mg} / \mathrm{L}), \mathrm{NH}_{4}-\mathrm{N}(0.47 \mathrm{mg} / \mathrm{L})$ and $\mathrm{PO}_{4}(0.07 \mathrm{mg} / \mathrm{L})$ reached the highest values in the first week of exposure and compared to the other sites, hence indicating pollution by both nutrients and organic xenobiotics, which apparently originated from a drainage dukt. The most important pesticides at Mörschwil were Carbendazim, Isoproturon, Diuron and to lesser extend Terbutryn, esp. in the second week of exposure. Although the downstream site Meggenmühle flows through an agricultural area it did not show any contamination peaks, whereas the site Steinach, just before the Häftlibach flows into lake Constance, had elevated pesticide concentrations only in the second week of exposure, the most important substances being Pirimicarb and Diuron (Table 2).

\subsection{GamTox ${ }^{\mathrm{TM}}$ : In Situ Survival and Feeding}

In the Hornbach catchment, GamTox ${ }^{\mathrm{TM}}$ verified good ecotoxicological water quality of the reference site in the Othmarbach with the best survival of gammarids (Figure 2). As expected, the gammarids exposed directly below the horticulture centre were under extreme pressure with significantly highest mortality starting after 2 weeks of exposure compared to gammarids exposed above the horticulture nursery $(\mathrm{p}<0.001)$, the downstream $(\mathrm{p}<$ $0.004)$ and the reference sites $(p<0.001)$. The increase in mortality corresponds to the chemical analyses which were taken during week 2 and 3 of the in situ test, show- 
Table 2. Nutrients and pesticides found in 2 subsequent weekly cumulative samples in the Häftlibach in May-June 2011. 1 w: $1^{\text {st }}$ week; 2 w: $2^{\text {nd }}$ week; Critical concentrations marked in red; Nd: not detected, i.e. below detection limit $(0.01 \mu g / L)$.

\begin{tabular}{|c|c|c|c|c|c|c|}
\hline Analyt & Mörschwil $1^{\text {st }} \mathrm{W}$ & Meggenm. $1^{\text {st }} \mathrm{W}$ & Steinach $1^{\text {st }} \mathrm{W}$ & Mörschwil $2^{\text {nd }} \mathrm{W}$ & Meggenm. $2^{\text {nd }} \mathrm{W}$ & Steinach $2^{\text {nd }} \mathrm{W}$ \\
\hline Temp $\left({ }^{\circ} \mathrm{C}\right)$ & 16 & 15 & 17 & 13 & 12 & 13 \\
\hline $\mathrm{pH}$ & 8.2 & 8.2 & 8.5 & 8.2 & 8.3 & 8 \\
\hline Cond. $(\mu \mathrm{S} / \mathrm{cm})$ & 624 & 686 & 612 & 580 & 502 & 341 \\
\hline Oxygen (mg/L) & 8.8 & 9.6 & 9.3 & 9.7 & 9.8 & 10.1 \\
\hline $\mathrm{DOC}(\mathrm{mg} / \mathrm{L})$ & 7.5 & 4.3 & 2.7 & 6.2 & 5.2 & 8.2 \\
\hline $\mathrm{CL}(\mathrm{mg} / \mathrm{L})$ & 33.7 & 51.3 & 50.4 & 16 & 25.7 & 26 \\
\hline $\mathrm{NH}_{4}-\mathrm{N}(\mathrm{mg} / \mathrm{L})$ & 0.4 & 0.04 & 0.04 & 0.05 & 0.04 & 0.1 \\
\hline $\mathrm{NO}_{2}-\mathrm{N}(\mathrm{mg} / \mathrm{L})$ & 0.03 & 0.01 & 0.01 & 0.03 & 0.01 & 0.02 \\
\hline $\mathrm{NO}_{3}-\mathrm{N}(\mathrm{mg} / \mathrm{L})$ & 1.9 & 2.5 & 1.6 & 1.7 & 2.6 & 5.1 \\
\hline P-ges. (mg/L) & 0.19 & 0.05 & 0.05 & 0.14 & 0.12 & 0.2 \\
\hline $\mathrm{SO}_{4}(\mathrm{mg} / \mathrm{L})$ & 12.6 & 13.2 & 15.1 & 9.4 & 10.6 & 14.1 \\
\hline Atrazin (ng/L) & 8 & 14 & 12 & 2 & 4 & 4 \\
\hline Diazinon (ng/L) & 4 & 6 & 5 & 4 & 4 & 14 \\
\hline Difenoconazol (ng/L) & 11 & 27 & 13 & 4 & 23 & 34 \\
\hline Dimethoat (ng/L) & $\mathrm{Nd}$ & $\mathrm{Nd}$ & $\mathrm{Nd}$ & 8 & 29 & 51 \\
\hline Iprodion (ng/L) & $\mathrm{Nd}$ & $\mathrm{Nd}$ & $\mathrm{Nd}$ & $\mathrm{Nd}$ & 70 & 100 \\
\hline Metolachlor (ng/L) & 1 & 2 & 2 & 2 & 4 & 8 \\
\hline Pirimicarb (ng/L) & 1 & 21 & 18 & 1 & 28 & 88 \\
\hline Simazin (ng/L) & 4 & 6 & 6 & 2 & 4 & 18 \\
\hline Carbendazim (ng/L) & 80 & 22 & 22 & 260 & 130 & 77 \\
\hline Isoproturon (ng/L) & 42 & 5 & 4 & 38 & 6 & 7 \\
\hline Diuron (ng/L) & 240 & 13 & 19 & 940 & 280 & 180 \\
\hline Terbutryn (ng/L) & 16 & 3 & 3 & 29 & 10 & 8 \\
\hline
\end{tabular}

ing elevated concentration levels of several substances. Responsible for this might be the high concentrations of nutrients (Nitrite, Ammonium and Phosphate) after the first rain event as well as the pesticides, esp. those being found only at that site or showing highest levels below the nursery. Examples are Endosulfan, Imidacloprid, Iprodion and Diazinon in the $3^{\text {rd }}$ week of exposure. Below the horticulture centre gammarids were lacking completely, even though they were abundant only about 100 $\mathrm{m}$ upstreams at the site above the horticulture centre. Above the horticulture centre gammarids survived as well as in the reference stream, the Othmarbach (p: ns). This indicates that nutrient and pesticide concentration levels above the horticulture centre did not affect the organisms during the first 4 weeks of exposure. However, during the last two weeks of exposure both sites, above and below the horticulture centre showed a parallel de- crease in survival of the gammarids, indicating that in this period diffuse agricultural pollution with both nutrients and pesticides along the whole stream might have been the relevant stressor for the animals. Gammarus pulex survival at the downstream site differed only slightly from the reference site $(p<0.023)$ and the site below the horticulture centre $(\mathrm{p}<0.004)$. Nutrient levels except P-tot were comparable, however some pesticides were higher downstream than in the Othmarbach, such as Diuron, Diazinon, MCPP, Metolachlor, AMPA, Glyphosat. Glyphosat was as high as at the sites above and below the horticulture nursery; Diuron was only found downstream. This shows, that the downstream site is affected by pesticide and phosphor loads, although survival of gammarids was only slightly affected. The site below the horticulture proved to be the most toxic site. Feeding behavior of the caged gammarids did not differ signifi- 


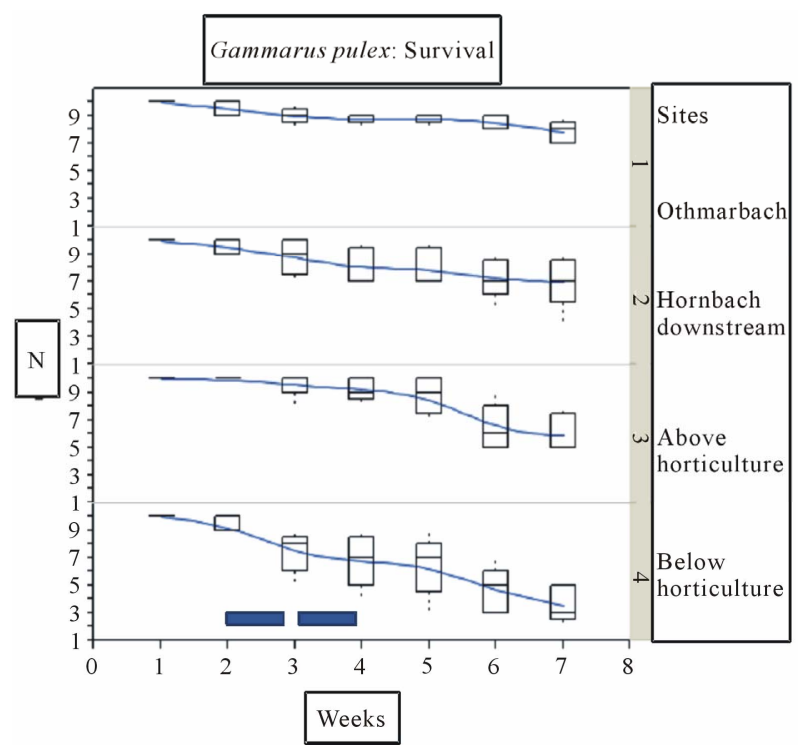

Figure 2. Survival of Gammarus pulex in Hornbach: least square fit (lines). Survival in absolute numbers. Boxwhisker plots (median, quartiles $(25 \%, 75 \%))$, extremes as dots. Sites 1 (reference), 2 (Hornbach downstream), 3 (above horticulture centre), 4 (below horticulture centre). Exposition: start 2.5.11 (date 1) to end 11.6.11 (date 7). Blue bars: weekly cumulative samples for water analysis.

cantly between the three sites and the reference site. The alder leaf was always consumed between $25 \%-50 \%$ within one week of exposure. This indicates that one alder leaf is sufficient to feed 10 gammarids during one week.

In the Häftlibach the site Mörschwil turned out to be a highly toxic place for gammarids as by the second week of exposure all animals had died in all cages (Figure 3). High nutrient loads (DOC, Ammonium and Phosphor) and pesticide values for Isoproturon and Carbendazim, Diuron and Terbutryn were maximal at this site, esp. during the $2^{\text {nd }}$ week of exposure and chemical sampling. This corresponds to the fact that at this site Gammarus spp. were lacking. At the other sites further downstream no significant mortality was recorded. Feeding rate did not differ significantly between sites, weekly feeding rates varied between $25 \%$ and $50 \%$, as in the Hornbach. However, during the $1^{\text {st }}$ week of exposure feeding tended to be already lower at Mörschwil compared to the other sites.

\section{Discussion}

\subsection{Test Performance}

GamTox ${ }^{\mathrm{TM}}$ proved to be easy to handle and reliable in the field. Gammarids could be exposed for up to 6 weeks with high survival rates at the reference site. Even during periods with very low water levels the cages still received flowing water and tolerated water temperatures up

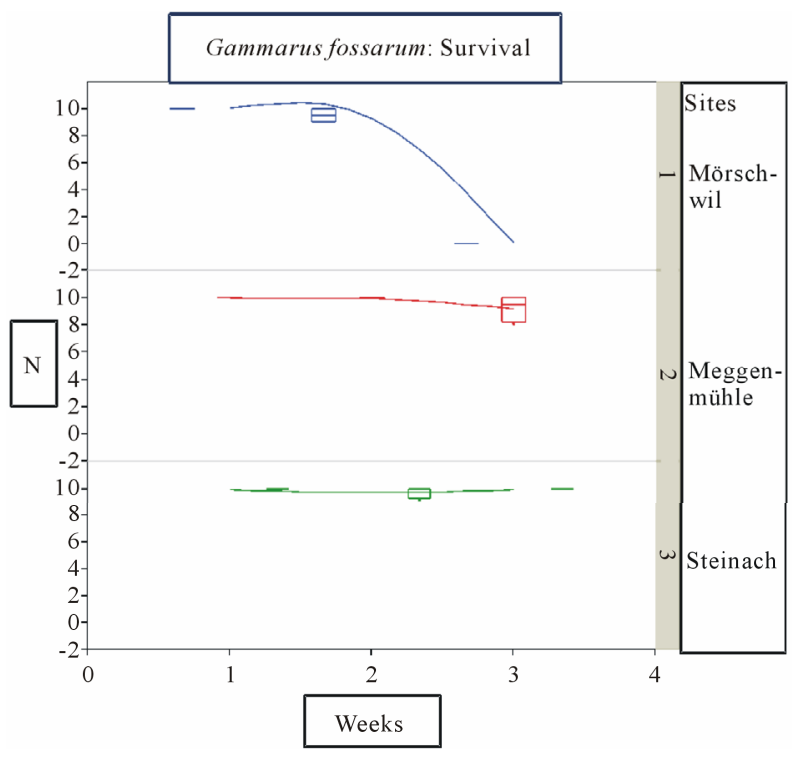

Figure 3. Survival of Gammarus fossarum in Häftlibach: least square fit (lines). Survival in absolute numbers. Boxwhisker plots (median, quartiles $(25 \%, 75 \%)$ ), extremes as dots. Sites 1 (Mörschwil), 2 (Meggenmühle), 3 (Steinach). Exposition: start 29.05.11 (date 1) to end 04.6.11 (date 3). Cumulative samples for water analysis in both weeks.

to $20^{\circ} \mathrm{C}$. Ten animals/per cage were sufficient to detect significant differences due to pollution, to avoid cannibalism and aggression and to feed on one alder leaf during the course of one week. Our test protocol differs from the other approaches using large leaf packages together with higher numbers of gammarids in bags made of nylon nets. These tests have originally been used to study leaf decay and/or colonization with invertebrates but not for specific in situ ecotoxicological experiments with gammarids [7]. There is a higher probability that small invertebrates enter leaf packages in nylon mesh bags compared to our plexiglass tubes. Moreover, loss of leaf material during decay might be increased in mesh bags. Our approach also differs from [12], who exposed 20 gammarids in opaque polyethylen cylinders $(10 \mathrm{~cm}$ length, $5.5 \mathrm{~cm}$ diameter) caped with nylon mesh $(1 \mathrm{~mm}$ mesh size) fixed in dark rigid plastic containers with a lid. Our transparent rigid plexiglass tubes provide good shelter as well as the natural diurnal photoperiod for the exposed animals. Moreover, we use small animals as they are more sensitive than adult gammarids.

Smaller mesh size also prevents other invertebrates from entering the cage. By providing lower animal density and larger space biotic interactions and stress are kept at a minimum in our method. Mesh size is smaller in order to avoid entrance of smaller invertebrates, which might grow and interact with the gammarids and/or the alder leaf during the long exposure time of up to 6 weeks. In order to avoid reproduction during long term exposures only males or juvenile gammarids might be forseen 
for the tests. Preference should be given to healthy animals from reference sites within the catchment of the location to be tested. The plexiglass tubes with screw rings are fast and easy to control and clean, hence practical for routine application. The tubes have been designed according to the test chambers of the automated online biomonitor Multispecies Freshwater Biomonitor ${ }^{\circledR}$, so that the in situ GamTox ${ }^{\mathrm{TM}}$ test may also be performed in an automated manner if an external power supply is available.

\subsection{Calibration of GamTox ${ }^{\mathrm{TM}}$ with Chemical Analyses}

GamTox $^{\mathrm{TM}}$ detected acute pollution due to acutely toxic Ammonium in the Häftlibach $(0.47 \mathrm{mg} / \mathrm{L})$ (LOEC of ingestion rate in amphipods at $0.18 \mathrm{mg} / \mathrm{L}$ [13]; increase in ventilation and decrease in survival at $0.10 \mathrm{mg} / \mathrm{L}$ (Osswald pers. comm.) combined with high DOC loads, as well as pesticide stress (esp. Diuron, Terbutryn and Carbendazim reaching the European Environmental Quality Standard levels). Whereas Diuron and Terbutryn toxicity towards crustaceans is low (Diuron LC50-48 h for daphnids ca. $1000 \mu \mathrm{g} / \mathrm{L}$, for gammarids idem; Terbutryn LC50-48 h for daphnids ca. $2600 \mu \mathrm{g} / \mathrm{L}$, for gammarids ca. $4000 \mu \mathrm{g} / \mathrm{L}$ [3], Carbendazim is a highly toxic fungicide recorded at almost acutely toxic levels at Mörschwil $(0.26 \mu \mathrm{g} / \mathrm{L}), \mathrm{LC} 50-96 \mathrm{~h}$ for gammarids: 1 - $10 \mu \mathrm{g} / \mathrm{L})$. In conclusion, the acute toxicity recorded within 2 weeks of exposure of Gammarus fossarum in the Häftlibach was most likely caused by a peak in Carbendazim in the $2^{\text {nd }}$ week of exposure at acute toxic levels combined with high Ammonium load in the first week, which might have made the animals even more susceptible to the pesticide pulse.

GamTox $^{\text {TM }}$ also detected chronic toxicity in the Hornbach due to elevated Nitrite and pesticides (e.g. Iprodion, Metolachlor, Terbutylazin, Diazinon, AMPA) at elevated concentration levels, but below acutely toxic levels for crustaceans cited in the literature (www.pesticideinfo.org). Especially Metolachlor was high in the $3^{\text {rd }}$ week of exposure at the sites above and below the horticulture centre, however still about 10 times less than acutely toxic levels for daphnids (D. magna: LC50-48 h: $26 \mu \mathrm{g} / \mathrm{L}$ ). High water temperature (up to $20^{\circ} \mathrm{C}$ ), and moderate nutrient levels did not disturb survival of the exposed gammarids. However, Nitrite values of 0.37 $0.3 \mu \mathrm{g} / \mathrm{L}$ in the $2^{\text {nd }}$ and $3^{\text {rd }}$ week of exposure below the horticulture reach actuely toxic levels of $>0.1 \mathrm{mg} / \mathrm{L}$ for fish larvae [14]. In conclusion, in the Hornbach high toxicity of Nitrite might contribute to their low survival below the horticulture centre supported by the lack of gammarids in the benthos. Pesticide levels were moderate at most sites and did not affect survival of gammarids that much compared to the site below the horticulture centre, where e.g. Endosulfan was one of the pesticides recorded explicitely there. Endosulfan has been shown to be acutely toxic to gammarids at $1-10 \mu \mathrm{g} / \mathrm{L}$ within $1-4$ days of exposure. Iprodion has an LC50-96 h of 3.46 $\mathrm{mg} / \mathrm{L}$ and a LOEC (Drift) of $0.36 \mathrm{mg} / \mathrm{L}$ in Gammarus pulex (AQUIRE). The levels in Hornbach below the horticulture centre are below these LOECs.

All mentioned pesticides, which were found in elevated levels and contributed to the observed toxicity are blacklisted by Greenpeace, most of them are being phasedout in the EU and some of them (esp. Diuron, Isoproturon) are taken up in the Annex II of Directive 2008/ 105/EC. Carbendazim and Terbutryn might exhibit endocrine effects [15]. Terbutryn has been observed to show lethal effects at $>4 \mathrm{mg} / \mathrm{L}$ in $G$. fossarum after $96 \mathrm{~h}$ of exposure [16]. $\mathrm{Cu}$ used as a pesticide showed acute toxic effects at $>50 \mu \mathrm{g} / \mathrm{L}$ in Gammarus pulex both in the laboratory [17] and in situ [18]. Taylor et al. [19] already noticed an EC50-96 h for feeding rate of G. pulex on Artemia eggs to be affected by $>12.1 \mu \mathrm{g} / \mathrm{L}$. The observed levels in the Hornbach are around $2-4 \mu \mathrm{g} / \mathrm{L}$ at all sites, hence in the range of chronic toxicity. The LC50$96 \mathrm{~h}$ value for Imidacloprid is $0.27 \mathrm{mg} / \mathrm{L}$ in Gammarus pulex, the LOEC (Drift) $0.03 \mathrm{mg} / \mathrm{L}$ (AQUIRE).

At the sites where gammarids did not occur in the benthos (Mörschwil in the Häftlibach and below the horticulture centre in the Hornbach) exposed gammarids suffered from high mortality, indicating that chemical stressors during the exposure time contribute seriously to the lack of gammarids at those sites. Whereas in the Häftlibach Carbendazim appeared to have most effect on survival, in the Hornbach Iprodion, Diazinon and Endosulfan appeared to contribute most to the observed toxic effects. However, all other pesticides, even at low levels and nutrient loads might have additively affected the survival of the gammarids. Therefore, the total sum of toxic units (TU) was calculated for each site and stream (Kaske \& Liess, pers. communication). The TU values are based on a comparison of concentration levels recorded and literature data on the toxicity of single substances for Daphnia spp. (mostly LC50-48 h values). In the Hornbach only the site Othmarbach showed a TU value of -2.55 , i.e. moderate pollution with pesticides, whereas all other sites showed values $>-2$, i.e. highly polluted (above horticulture: -0.9 , below horticulture: -1.1 , dowmstream: -1.07$)$. Generally the TU concept could prove that the Othmarbach is less affected by pesticides than the Hornbach, however there was no finer distinction possible between the three sites in the Hornbach, whereas GamTox ${ }^{\mathrm{TM}}$ proved significant differences. In the Häftlibach the TU values showed moderate pollution at Mörschwil, which proved to be the most toxic site with $\operatorname{GamTox}^{\mathrm{TM}}$ (TU: -2.2) and Meggenmühle (TU: 
-2.1 ), whereas high pollution at Steinach (TU: -1.3$)$. The TU concept underestimated the toxicity at Mörschwil and overestimated the toxicity at Steinach. The underestimation of the toxicity at Mörschwil (Carbendazim, Ammonium) and Hornbach below the horticulture (Iprodion, Nitrite) might be due to the fact that not only pesticides but also nutrients might have contributed to the observed toxicity of gammarids in situ. Moreover, the basic data set for the TU-calculation are from literature data on daphnids, which not always show similar sensitivity towards pesticides compared to gammarids. Furthermore, the literature data are from 48-h exposures at constant concentration levels, whereas in situ mostly pulse pollution occurs, i.e. shorter exposures but often to higher concentration levels. Unfortunately our gross water samples represent levels averaged over one week, i.e. single pulses of high concentrations are unknown. Last but not least we summed up all TU values for each substance, where there were toxicity data for daphnids from literature, ignoring potential interactions between the substances such as synergism or antagonism. These uncertainties reveal that the TU-approach can only give a very rough estimate of the pollution at a site. In situ ecotoxicity tests, esp. with locally relevant species can tell us the real effects of contamination by mixtures of nutrients and xenobiotics, at a defined site and time.

\subsection{Correlation of $\operatorname{GamTox}^{\mathrm{TM}}$ with Bioassessment Methods (IBCH)}

$\operatorname{GamTox}^{\mathrm{TM}}$ demonstrated indicator suitability as it responded sensitively to a mixture of locally relevant chemical substances in both brooks, where long term bioassessment methods did not indicate problems in water quality: the IBCH index (Index Biologigue adapted to Switzerland) indicated moderate water quality in the Hornbach below the horticulture centre (IBCH 11), where exposed gammarid mortality was highest, whereas survival was moderately at the site close to lake Constance where the IBCH indicated unsatisfactory values (IBCH 7). At the two sites where exposed gammarids survived the best (Othmarbach and Hornbach above the horticulture) the IBCH corresponded with the results of GamTox ${ }^{\text {TM }}$ with slightly better values (IBCH 12 Othmarbach, IBCH 13 above the horticulture centre (LubiniFerlin: pers. comm.). The IBCH managed to differentiate between the sites above (good) and below (moderate) the horticulture centre, even though the benthos samples were taken during a rain period, where gammarids from above the horticulture centre drifted downstream and hence were collected where they normally do not occur. In the Häftlibach, the benthos at both Mörschwil (IBCH 9) and Steinach (IBCH 8) was classified as unsatisfactory/bad, however surivial of exposed gammarids was only affected at Mörschwil (Table 3).

The lack of gammarids could be explained with the current GamTox ${ }^{\mathrm{TM}}$ tests in both streams, while the IBCH was not indicative to explain the lack of gammarids. Whereas the IBCH is a biological measure, GamTox ${ }^{\mathrm{TM}}$ proved to be an ecotoxicological measure of chemical stress, which turned out to be the main stressor for sustainable gammarid populations at the problem sites in the two brooks. The IBCH method considers several macrobenthos taxa in both taxa diversity and abundance, the taxa being classified generally as sensitive/tolerant based on experience and mostly not on pesticide pollution data. The SPEAR Index (SPEcies at Risk) is based on macrobenthos data, but tries to include ecotoxicological information as well as other ecological information (e.g. migration, recolonisation) in one index [20]. The SPEAR Index classified the reference site at Othmarbach as good/moderate, corresponding to low chemical pollution and good survival in the GamTox ${ }^{\mathrm{TM}}$ test. All three sites

Table 3. Comparison of different water quality indices.

\begin{tabular}{|c|c|c|c|c|}
\hline Stream/site & IBCH & Toxic Unit (Sum) Toxicity & SPEAR Pesticides Index & GamTox $^{\mathrm{TM}}$ Survival (\%) \\
\hline Hornbach & & & & 6 weeks \\
\hline Othmarbach & 12: moderate & $-2.55:$ moderate & 34: good & $80 \%$ : good \\
\hline above hort. & 13: good & -0.9 : high & 24: moderate & $60 \%$ : mod./good \\
\hline below hort. & 11: moderate & -1.1 : high & 19: poor & $30 \%$ : poor \\
\hline downstream & 7: bad & $-1.07:$ high & 12: bad/poor & $70 \%:$ good \\
\hline Häftlibach & & & & 2 weeks \\
\hline Mörschwil & 9: moderate & $-2.2:$ moderate & 33: moderate/good & $0 \%$ : bad \\
\hline Meggenmühle & 11: moderate & $-2.1:$ moderate & 55: good & $90 \%$ : very good \\
\hline Steinach & 8: bad & -1.3 : high & 37: good & $90 \%$ : very good \\
\hline
\end{tabular}


along Hornbach were classified as moderate - unsatisfactory/bad by the SPEAR index, a distinction could be made between the sites above (SPEAR moderate/unsatisfactory) and below (SPEAR unsatisfactory) the horticulture centre (Kaske \& Liess pers. comm.). However, below the horticulture nursery, much more pesticides were found in higher concentrations as above, i.e. the toxic pressure was higher. The small difference in the SPEAR Index at these two sites might be due to the fact that the downstream drifted gammarids were taken into the calculation. This shows that benthos sampling is highly dependent on coincidences. The worst site according to the SPEAR index in the Hornbach is the downstream site (SPEAR: unsatisfactory/bad), which also differs in the taxa composition (many Diptera, esp. Chironomidae). In the Häftlibach, Mörschwil was the most polluted and highly toxic site, both by nutrient loads and pesticides, however the SPEAR pesticides index responded only to pesticides and classified this site as moderate in spite of high toxic effects on caged gammarids. Adaptation of the SPEAR index to toxicant mixtures, re-evaluation of certain taxa, and Gammarus toxicity data instead of Daphnia toxicity data as reference values might improve its indicative power.

\section{Conclusion}

GamTox $^{\mathrm{TM}}$ is a more sensitive indicator of biologically relevant contaminant stress in streams than the biological water quality index IBCH. Where the SPEAR pesticides index does not correlate with GamTox ${ }^{\mathrm{TM}}$ other sources of pollution than pesticides might be important stressors, too. As both the SPEAR Index and the IBCH depend on the same basis data set, errors and coincidences during sampling (e.g. sampling drifting animals instead of viable populations) affect the quality of the indices. GamTox ${ }^{\mathrm{TM}}$ reveals the integrative local toxic effects of both nutrient loads and all toxicants in the water during the exposure period, whereas chemical analysis can only account for a subset of toxicants and selected exposure time (automated samplers), hence giving an incomplete and erraneous picture in case pollution occurs by short pulses with high concentration levels.

\section{Acknowledgements}

This study was co-financed by the European Fund for REgional development (EFRE) and the Swiss cantonal fund within the programme Interreg IV "AlpenrheinBodensee-Hochrhein" on the project "Ökotoxikologischer Index im Bodenseeraum" (Nr. 227). The Canton Thurgau is kindly acknowledged for co-financing the Hornbach study. LimCo International $\mathrm{GmbH}$ contributed to the financial support, too and S. Gerhardt is thanked for assistance in the field. Detailled results about the macrobenthos and the SPEAR Index will be published elsewhere, V. Lubini, M. Liess and O. Kaske are acknowledged for personal communications on part of the results on IBCH and SPEAR index.

\section{REFERENCES}

[1] A. Gerhardt, L. Janssens de Bisthoven and A. M. V. M. Soares, "Macroinvertebrate Responses to Acid Mine Drainage: Community Responses and Online Behavioural Toxicity Bioassay," Environmental Pollution, Vol. 130, No. 2, 2004, pp. 263-274. doi:10.1016/j.envpol.2003.11.016

[2] A. Gerhardt, L. Janssens de Bisthoven and A. M. V. M. Soares, "Evidence for the Stepwise Stress Model: Gambusia holbrooki and Daphnia magna under AMD and ACID Stress," Environment Science \& Technology, Vol. 39, No. 11, 2005, pp. 4150-4158. doi:10.1021/es048589f

[3] A. Gerhardt, "GamTox" ${ }^{\mathrm{TM}}$ : A Low-Cost Multimetric Ecotoxicity Test with Gammarus spp. for in and ex situ Application," International Journal of Zoology, 2011, Article ID: 574536.

[4] M. Bundschuh, J. P. Zubrod and R. Schulz, "The Functional and Physiological Status of Gammarus fossarum Exposed to Secondary Treated Waste Water," Environmental Pollution, Vol. 159, No. 1, 2011, pp. 244-249. doi:10.1016/i.envpol.2010.08.030

[5] O. Geffard, A. Chaumot, B. Ferrari and B. Montuelle, "Les Expérimentations in Situ: Principes et Perspectives," Sciences Eaux et Territoires, Vol. 1, 2010, pp. 20-25.

[6] M. Bloor and C. J. Banks, “An Evaluation of Mixed Species in Situ and ex situ Feeding Assay: The Related Responses of Asellus aquaticus and Gammarus pulex," Environment International, Vol. 32, No. 1, 2006, pp. 22-27.

[7] L. Maltby, S. A. Clayton, R. M. Wood and N. McLoughlin, "Evaluation of the Gammarus pulex in Situ Feeding Assay as a Biomonitor of Water Quality: Robustness, Responsiveness and Relevance," Environmental Toxicology \& Chemistry, Vol. 21, 2002, pp. 361-368. doi:10.1897/1551-5028(2002)021<0361:EOTGPI >2.0.C $\mathrm{O} ; 2$

[8] P. Kunz, C. Kienle and A. Gerhardt, "Gammarus spp. in Aquatic Ecotoxicology and Water Quality Assessment: Towards Integrated Multilevel Tests," Environmental Toxicology \& Chemistry, Vol. 205, 2010, p. 76.

[9] A. J. Garmendia Tolosa and B. Axelsson, "Gammarus, Their Biology, Sensitivity and Significance as Test Organisms," Swedish Environmental Research Institute, Stockholm, 1993.

[10] A. Gerhardt, "Biomonitoring of Polluted Waters-Reviews on Actual Topics,” TTP, Zürich, 1999.

[11] A. Gerhardt, "Gammarus spp., Rückgang oder Fehlen von Bachflohkrebsen (Gammarus spp.) in Bächen," AquaPlus, 2010.

[12] R. Coulaud, O. Geffard, B. Xuereb E. Lacaze, H. Quéau, J. Garric, S. Charles and A. Chaumot, "In Situ Feeding Assay with Gammarus fossarum (Crustacea): Modelling the Influence of Confounding Factors to Improve Water Quality Biomonitoring," Water Research, Vol. 45, No. 19, 
2011, pp. 6417-6429. doi:10.1016/j.watres.2011.09.035

[13] A. Alonso and J. A. Camargo, "Toxic Effects of Unionized Ammonia on Survival and Feeding Activity of the Freshwater Amphipod Eulimnogammarus toletanus (Gammaridae)," Bulletin of Environmental Contamination and Toxicology, Vol. 72, No. 5, 2004, pp. 1052-1058. doi:10.1007/s00128-004-0350-Z

[14] W. H. Baur, "Gewässergüte Bestimmen und Beurteilen" Paul Parey, Hamburg, 1987.

[15] W. Reuter and L. Neumeister, "Die SCHWARZE LIste der Pestizide II," Greenpeace, Hamburg, 2010.

[16] T. Gildemeister, "Toxikokinetische Untersuchungen von Fenoxycarb bei Ausgewählten Organismen," Diplomarbeit, TU Dresden, Fakultät Mathematik und Naturwissenschaften, Institut für Hydrobiologie, 2000.

[17] A. Gerhardt, "Monitoring Behavioural Responses to Me- tals in Gammarus pulex with Impedance Conversion," Environmental Science and Pollution Research, Vol. 2, No. 1, 1995, pp. 15-23. doi:10.1007/BF02987506

[18] A. Gerhardt, A. Carlsson, C. Ressemann and K. P. Stich, "New Online Biomonitoring System for Gammarus pulex: In Situ Test below a Copper Effluent in South Sweden," Environmental Science and Technology, Vol. 32, No. 1, 1998, pp. 150-156. doi:10.1021/es970442j

[19] E. J. Taylor, D. P. W. Jones, S. J. Maund and D. Pascoe, "A New Method for Measuring the Feeding Activity of Gammarus pulex (L.)," Chemosphere, Vol. 26, No. 7, 1993, pp. 1375-1381. doi:10.1016/0045-6535(93)90188-B

[20] M. Liess and P. C. von der Ohe, "Analyzing Effects of Pesticides on Invertebrate Communities in Streams," Environmental Toxicology \& Chemistry, Vol. 24, No. 4, 2005, pp. 954-965. 